\title{
RUDENESS DIFFERS: TO THE 20th ANNIVERSARY OF LINGUISTIC IMPOLITENESS RESEARCH
}

\author{
Viktor V. Leontyev \\ Volgograd State University, Volgograd, Russian Federation
}

\begin{abstract}
Linguistics as well as any other science has been developing systematically, bringing absolutely new objects into the sphere of its interests. The contemporary linguistics studies, among other subjects, the phenomena of everyday speech actions of communicants which in the recent past were not considered to be the object of linguistic research.

Linguistics has been recently paying special attention to a number of socio-pragmatic categories which emphasize the significance of language as the basic instrument of communication.

Both politeness and impoliteness as its logical antipode seem to be among the most dynamically developing objects of research by contemporary pragmaticians and sociolinguistists.

Taking into consideration the publications of the last decade, the article systematizes the achievements of foreign linguists in impoliteness research. Firstly, the article briefly surveys the early, so called "post-BrownLevinsonian" linguistic works on impoliteness. Secondly, the article surveys a number of contemporary discourse theories of impoliteness, including the so-called "post-modern" and sociological (interactional) approaches to the study of politeness / impoliteness. The author pays special attention to the point of main disagreements between impoliteness theorists, in particular, to the point of taking / not taking into account intentions of producers of impolite / rude utterances and the point of terminological duality: what type of speech actions should be called ruden and what type of speech actions should be called impolite.

Key words: politeness, impoliteness, rudeness, communication, communicative strategy, impoliteness theory, speech behavior, emotion.
\end{abstract}

УДК $81: 177.1$

Дата поступления статьи: 29.09.2016

ББК 81.006

Дата принятия статьи: 28.10.2016

\section{ГРУБОСТЬ ГРУБОСТИ РОЗНЬ: К 20-лЕТИю ИССЛЕДОВАНИЙ РЕЧЕВОЙ НЕВЕЖЛИВОСТИ В ЛИНГВИСТИКЕ}

\author{
Виктор Владимирович Леонтьев \\ Волгоградский государственный университет, г. Волгоград, Российская Федерация
}

\begin{abstract}
Аннотация. Языкознание, как и любая другая наука, развивается планомерно, постепенно включая в сферу своих интересов все новые и новые объекты. Современное языкознание изучает явления повседневной речевой деятельности коммуникантов, в недалеком прошлом не считавшиеся объектом лингвистических исследований.

В последнее время лингвистика обращает особое внимание на социально-прагматические категории, подчеркивающие значимость языка как основного инструмента коммуникации.

Одним из самых динамично развивающихся направлений современной прагматики и социолингвистики является изучение вежливости, а с недавних пор и невежливости как логического антипода вежливости.

В статье с учетом публикаций последнего десятилетия систематизированы достижения зарубежных лингвистов в изучении феномена невежливости. Во-первых, кратко охарактеризованы ранние, так называемые «пост-браун-левинсоновские», трактовки невежливости. Во-вторых, представлен обзор некоторых наиболее значимых современных теорий невежливости, включающий и те, которые основаны на дискурсивном («постмодернистском») и социологическом (интеракциональном) подходах к изучению вежливости / невежливости. Особое внимание уделено основным разногласиям между теоретиками невежливости, в частности относительно необходимости учитывать интенции адресантов при анализе невежливых и грубых выс-
\end{abstract}


казываний и относительно того, какой тип высказываний следует отнести к проявлению невежливости, а какой - к проявлению грубости.

Ключевые слова: вежливость, невежливость, грубость, коммуникация, коммуникативная стратегия, теория невежливости, речевое поведение, эмоция.

\section{1. Введение.}

В последние десятилетия лингвисты уделяют все большее внимание анализу речевой деятельности человека и, шире, межличностным отношениям, поскольку речевая деятельность играет важную роль в правильном конструировании этих отношений совместными усилиями коммуникантов. Одной из самых исследуемых речеведческих тем в мировой прагматике и социолингвистике является тема вежливости - социопрагматического феномена, представляющего собой своеобразный «фундамент» при формировании межличностных отношений.

Однако эти отношения не всегда нацелены только на кооперативное, вежливое общение. Нормой общения может быть и невежливость, даже грубость как крайняя степень проявления невежливости. Иными словами, вежливость и грубость представляют собой речевые инструменты коммуникативного баланса [3, с. 258].

Поэтому мы кратко остановимся на анализе социально-прагматического феномена вежливости как предмете изучения лингвистики, затем перейдем непосредственно к анализу невежливости как логического антипода вежливости, посвятив основную часть статьи обзору трудов зарубежных ученых по проблемам речевой невежливости. Отметим, что в работах зарубежных лингвистов по некооперативному (не)речевому поведению используется не только термин «невежливость» («impoliteness»), но и термин «грубость» («rudeness»), что обусловлено дуальностью взглядов на эти логически весьма близкие оценочные терминологические единицы, причем данные термины часто употребляются недифференцированно.

\section{2. Вежливость / невежливость как объект изучения.}

Вежливость интересна как объект исследования уже потому, что существует удивительное разнообразие мнений рядовых носителей языка по вопросу точного определения ее сущности. Если одни понимают под веж- ливостью правильное с социальной точки зрения или уместное поведение, то другие считают, что вежливость является признаком образованности. В понимании одних вежлив тот, кто всегда проявляет внимание к собеседникам, по мнению других, вежлив тот, кто всегда держится в тени $[69$, р. 1]. Таким образом, вежливость представляет собой сложное социально-культурное явление. Она связана с основными принципами социокультурной организации общества и межличностными отношениями, существующими между его членами, с их коммуникативным сознанием $[4$, c. 30]. Цель ее изучения на теоретическом уровне заключается в понимании того, как люди успешно управляют межличностными отношениями для достижения личных и групповых интересов [67, p. 1].

При исследовании вежливости основное внимание лингвистов уделяется фактору адресата, поскольку именно адресат оценивает речевые и неречевые действия адресанта как вежливые / невежливые. При этом данная оценка не только вербальна: высказывание «становится значимым и интерпретируемым... при взаимодействии вербальных, кинетических и просодических действий в контексте» $[14$, p. 248$]$.

Особую сложность представляет изучение вежливости в межкультурном плане, что объясняется ее национально-специфичным характером: для каждой культуры характерен свой набор речевых стратегий вежливости. Поэтому (не)речевое поведение, воспринимаемое в одной культуре как вежливое, в другой может быть воспринято как грубое [2, с. 103; 3 , с. $258 ; 5$, с. $35 ; 6$, с. $126 ; 7$, с. 257$]$. Грубость в той же мере, что и вежливость, отражает национальные социально-культурные ценности, но с противоположным знаком [3, с. 259]. Вежливость целесообразно рассматривать не столько на фоне общекультурных норм, в той или иной мере известных всем взрослым представителям одной национальной культуры, сколько на фоне норм, принятых и признаваемых в конкретном сообществе по интере- 
сам («community of interests»), например, среди футбольных болельщиков или в конкретном коллективе («community of practice»), занятом единым для всех его участников видом деятельности.

При анализе любого (не)речевого действия нельзя не учитывать влияние на восприятие конкретного высказывания как вежливого или грубого многих социальных факторов: фактора классовой принадлежности коммуникантов, факторов их возрастных, статусных, гендерных различий и, повторим еще раз, фактора различий в степени их образованности. Нормы восприятия вежливости / невежливости варьируются в зависимости от этих переменных. Именно поэтому (не)речевое поведение, оцениваемое как грубость, например, российскими пенсионерами, совершенно нормативно и зачастую не считается грубым для россиян 20-30 лет, не вызывая у них никаких отрицательных эмоций, переживаемых их более старшими адресатами. В одной из наших предыдущих работ показано, что фразы, оцениваемые как некие «грубые солености (похабщина)» представителями интеллигенции, если они касаются внешности женщин, могут восприниматься как довольно высокая оценка природных данных представительниц слабого пола людьми из малообразованных слоев общества в силу того, что уровень их коммуникативной компетенции не позволяет им сделать классический комплимент [7, с. 257].

Таким образом, на ожидания коммуникантов от конкретного высказывания (об «уровнях» ожиданий коммуникантов см. ниже) влияют все указанные факторы: «в одних условиях партнер вправе услышать от говорящего вежливое обращение, в других ожидает услышать грубость» [3, с. 259].

\section{3. Становление лингвистических} подходов к изучению невежливости.

В силу многогранности вежливости и еще бо́льшей многогранности невежливости и грубости, исследования этих социопрагматических категорий ведутся на пересечении лингвопрагматики и социолингвистики, речеведения и методики преподавания иностранных языков, психологии, социологии и социальной антропологии, культурологии и гендерных исследований [21, p. 2]. С 2005 г. немецкое изда- тельство «Walter de Gruyter» издает специализированный международный журнал «Journal of Politeness» для публикаций по данной теме.

Благодаря постепенному пониманию лингвистами и психологами того факта, что в процессе коммуникации адресату часто невозможно однозначно интерпретировать конкретное высказывание как вежливое или грубое, в научном обиходе современной зарубежной прагматики закрепился зонтичный термин «linguistic (im)politeness» («лингвистическая (не)вежливость») для обозначения как ликоусиливающих, так и лико-ущемляющих речевых действий, хотя многие зарубежные ученые по-прежнему используют термины «linguistic politeness» и «linguistic impoliteness».

Если сравнить масштаб исследований вежливости, невежливости и грубости в мировой науке, то становится очевидным тот факт, что исследование невежливости и грубости как направления в лингвистике до сих пор во многом переживает период становления [19, p. 101; 64]. Тому есть объективные причины.

Авторы классических (прагматических) теорий вежливости P.T. Лакофф (R.T. Lakoff) [53], П.Браун (P. Brown) и С. Левинсон (S. Levinson) [20], Дж. Лич (G. Leech) [54], Б. Фрезер (В. Fraser) и У. Нолен (W. Nolen) [33] не уделяли значительного внимания анализу невежливых и грубых (не)речевых действий в силу ряда концептуальных недочетов созданных ими теорий. Они анализировали отдельные речевые акты, часто рассматривая их вне всякого контекста, что, по-видимому, не позволяло найти надежный способ дифференцировать вежливые и невежливые / грубые речевые действия.

В связи с этим М. Лохер (М. Locher) и P. Уоттс (R. Watts) классифицируют универсальную теорию вежливости П. Браун и С. Левинсона как теорию уместных или вежливых речевых действий, предпринимаемых по сохранению социальных лиц коммуникантов [56, p. 10]. Такая трактовка значительно упростила сущность понятия «facework», которое oxватывало в социологической теории Э. Гофмана (E. Goffman) [35], ставшей теоретическим базисом для работы П. Браун и С. Левинсона, весь спектр речевых действий: от лико-усиливающих до лико-ущемляющих. 
Первые исследования, посвященные анализу невежливости и грубости, появились вскоре после публикации в 1978 г. (второе, монографическое издание вышло в 1987 г.) работы П. Браун и С. Левинсона. К ранним «пост-браун-левинсоновским» трудам по невежливости и грубости относятся публикации $[16 ; 17 ; 22 ; 48 ; 51 ; 62]$.

Этапными работами можно назвать статьи Л. Лэхенихта (L.G. Lachenicht) [51] и Дж.П.М. Остин (J. P. M. Austin) [16], которые написаны в русле универсальной теории вежливости. При этом статья Л. Лэхенихта (как и работа П. Браун и С. Левинсона) адресантоцентрична, поскольку автор уделяет основное внимание анализу речевого «нападения» на социальное лицо адресата со стороны адресанта («face-attack»), то есть процессу генерации невежливого общения, в то время как Дж.П.М. Остин первой из всех лингвистов при анализе невежливого коммуникативного поведения постулировала значимость фактора адресата: в центре ее внимания находится восприятие адресатом высказываний, которые он может считать обидными (оскорбительными) для себя.

В статье Р. Крейга, К. Трейси и Ф. Спайсек (R. Craig, K. Tracy, F. Spisak) впервые выдвинута идея о том, что любое, даже самое кооперативное, действие может обладать враждебными обертонами, например, в речевом акте «Compliment» может имплицитно содержаться некая критика адресата. Тем самым авторы расширили теорию П. Браун и С. Левинсона, включив в список речевых стратегий «facework» как кооперативные, смягчающие угрозу социальным лицам коммуникантов стратегии (cooperative, mitigating strategies), так и стратегии с прямо противоположным значением (aggravating strategies) [22, p. 456-461].

Сложностью феномена речевой невежливости можно объяснить богатство терминов для его обозначения в лингвистике. Один и тот же предмет анализа получает различные наименования у разных авторов: «роsitive and negative aggravation» (нанесение урона позитивному и негативному лицу) [51, p. 622 632]; «aggravation» (ухудшение взаимоотношений) [22, p. 456-461]; «aggravating the face» (нанесение урона социальному лицу) [62, p. $22-$
26]; 《rudeness» (грубость, невежливость, оскорбительность) [48, p. 208-211; 52, p. 103104]; «face-attack» (нападение (атака) на социальное лицо) [16, p. 281-290]; «impoliteness» (невежливость) [28]. В статье Дж.П.М. Остин невежливость была образно и точно названа «темной стороной вежливости (“the dark side of politeness")» [16].

На современном этапе изучение невежливого и грубого коммуникативного поведения оказывается в сфере интересов и отечественных лингвистов (см.: [2; 3; 5; 6-13]).

Исходя из «пионерского» характера работ зарубежных ученых, посвященных невежливости, проанализируем достижения европейских и американских лингвистов в изучении этого феномена за последние годы.

\section{4. Основные направления изучения невежливости в современной зарубеж- ной лингвистике.}

Последнее десятилетие в истории мировой прагматики и социолингвистики характеризуется обилием изданных работ по невежливости. Во-первых, вышли две авторские монографии $[18 ; 27]$ и две коллективные монографии [15; 39]. Во-вторых, исключительно анализу невежливости посвящены специальные выпуски ряда авторитетных зарубежных журналов [40; 43-46; 63]. В-третьих, практически в каждом выпуске «Journal of Politeness Research» и во многих выпусках «Journal of Pragmatics» публикуются статьи по разным проблемам изучения невежливости. В-четвертых, вопросы, связанные с невежливостью, широко освещаются в нескольких коллективных монографиях, посвященных разным аспектам и методикам изучения межличностных отношений $[29 ; 41 ; 42 ; 61 ; 65]$.

Расширение горизонтов изучения вежливости привело к появлению ряда новых теоретических подходов и в изучении невежливости: а) дискурсивного («постмодернистского»); б) фреймового; в) когнитивного, рассматривающего вежливость как социальную норму, то есть в терминах классического подхода Б. Фрезера - У. Нолена; г) интеракционального; д) социально-психологического.

Охарактеризуем некоторые из перечисленных подходов.

Сторонниками дискурсивного («постмодернистского») подхода являются Г. Илен 
(G. Eelen) [30; 31], М. Кинпоинтнер (M. Kienpointner) [49; 50], M. Лoxep (M. Locher) [55-57], Р. Уоттс (R. Watts) [56; 57; 67-69], C. Миллз (S. Mills) [58-60] и ряд других ученых.

В отличие от подходов, реализованных в классических теориях вежливости, этот подход предполагает необходимость контекстуального, ситуативно обусловленного анализа (не)вежливости. В центре внимания ученых находится «алгоритм» всех действий коммуникантов, позволяющих им прийти к выводу о том, что то или иное высказывание следует оценить как вежливое / невежливое. В работах показано показано, каким образом полученная информация и наблюдаемые примеры коммуникативного поведения помогают коммуникантам сделать такой вывод [29, р. 5].

В рамках данного подхода различаются идеологии Politeness ${ }_{1}$ и Politeness 2. Politeness $_{1}$ объединяет набор норм, которыми руководствуются в повседневном общении рядовые носители языка при оценивании речевых действий как вежливых, a Politeness 2 обозначает интерпретацию вежливости как научного специального термина в теоретических изысканиях ученых [30]. Соответственно термины Impoliteness $s_{1}$ и Impoliteness ${ }_{2}$ применимы для интерпретации речевых действий как невежливых (грубых) на бытовом и научном уровне.

Сторонники дискурсивного подхода обращают пристальное внимание на социальный характер (не)вежливости [37]. Они рассматривают разговор, беседу как процесс, интерпретируя (не)вежливость как некое динамическое явление [60, p. 38; 69, p. 222-246].

Считая, что (не)вежливость не связана «намертво» с определенными лингвистическими формами и функциями, «постмодернисты» призывают к анализу гораздо бо́льших, чем отдельные предложения или высказывания, фрагментов аутентичного ежеминутного взаимодействия коммуникантов, именуемого метатермином «relational work» - деятельность коммуникантов по созданию межличностных взаимоотношений между собой, которая включает в себя весь спектр вербального и невербального поведения коммуникантов (от прямого, то есть грубого, агрессивного, речевого поведения до вежливого речевого поведения) [56, p. 11; 57, p. 78].
Согласно этой теории, оценка конкретного высказывания как вежливого, невежливого, грубого происходит непосредственно в ходе взаимодействия коммуникантов на основании их норм и ожиданий, ранее сформированных у них через категоризацию личного социального опыта в схожих ситуациях, причем эти нормы и ожидания могут изменяться со временем $[57$, p. 78].

К числу наиболее актуальных, сложных и до конца не решенных теоретических вопросов в области исследования невежливости в целом относится вопрос о том, каким образом адресату следует учитывать интенции адресанта при оценке его коммуникативного поведения как невежливого (грубого). Сложность вопроса объясняется тем фактом, что интенции любого коммуниканта точно определить очень трудно, за исключением так называемых «правдоподобных интенций» при условии наличия достаточных оснований у адресата считать их таковыми [26, p. 1552].

Поскольку конкретное (не)речевое действие оценивается как (не)вежливое адресатом, а не самим адресантом, то значительно важнее понять то, какие личные и социальные факторы влияют на оценочное восприятие адресатом данного (не)речевого действия как грубого, унижающего его «социальное лицо», то есть его (ее) образ не столько в его (ее) глазах, сколько в глазах других коммуникантов.

Обратим внимание на позицию Р. Уоттса и М. Лохер, согласно которой восприятие коммуникантами интенций своих собеседников, а не сами интенции определяют, будет ли конкретное (не)речевое действие отнесено к категории вежливых или грубых [57, p. 80].

С вопросом анализа интенций адресанта напрямую связан не менее сложный вопрос терминологического разграничения этих коммуникативных феноменов: каким термином («impoliteness» или «rudeness» в английском языке, «невежливость» или «грубость» в русском языке) следует обозначать интенциональное лико-ущемляющее (не)речевое действие.

Так, в работе М. Кинпоинтнера (M. Kienpointner) феномен невежливости анализируется с научной точки зрения, то есть как специальный термин «Impoliteness 2 ». 
В этой концепции термины «impoliteness» и «rudeness» синонимичны [49, p. 245]. Невежливость / грубость означает прототипическое некооперативное коммуникативное поведение, дестабилизирующее взаимоотношения коммуникантов, затрудняющее достижение ими общей коммуникативной цели и создающее (поддерживающее) эмоциональное состояние неприятия, антипатии, служащее эгоцентрическим целям адресантов и частично определяемое признаваемыми в данном сообществе понятиями власти, социальной дистанции и эмоциональных отношений [49, p. 245].

Ценность такого понимания сути феноменов невежливости / грубости заключается, по нашему мнению, в опоре на важнейшее для анализа невежливости понятие эмоции, которому не всегда уделяется должное внимание в работах, где анализируется невежливость / грубость.

Адресат может испытать только отрицательные эмоции в случае оценки им (не)речевого поведения адресанта как грубого, в то время как адресант, даже если он / она осознает степень своей грубости, не может пережить такие же эмоциональные последствия $[38$, p. 68]. Насущная необходимость учитывать эмоции адресатов грубых (не)речевых действий подтверждается тем, что коммуниканты склонны ассоциировать с подлинными эмоциями не вежливость, а именно невежливость и грубость [34, p. 69; 49, p. 244].

В терминах сторонницы фреймового подхода в изучении (не)вежливости М. Теркурафи (M. Terkourafi) лексема rudeness в английской культуре обозначает осознаваемую, то есть намеренную грубость, а лексема impoliteness - случайную, ненамеренную угрозу лицу адресата со стороны говорящего (адресанта) [66, p. 62].

Дифференцируя маркированную и немаркированную вежливость, маркированную и немаркированную грубость и невежливость, М. Теркурафи уточняет, что при немаркированной грубости конкретное высказывание конвенционально контексту, в котором угроза социальному лицу адресата ожидаема до степени, гомологичной габитусу коммуникантов. При маркированной грубости конкретное высказывание неконвенционально контексту. При этом посредством распознавания адресатом интенций адресанта маркированная грубость угрожает социальному лицу адресата и в итоге - социальному лицу самого адресанта в глазах адресата или другого коммуниканта. Невежливость фиксируется в том случае, когда конкретное высказывание неконвенционально контексту, оно несет угрозу социальному лицу только адресата, при этом адресат не приписывает адресанту никакой лико-угрожающей интенции [66, p. 70].

Иначе, чем М. Кинпоинтер и М. Теркурафи, трактует невежливость и грубость Дж. Калпепер (J. Culpeper), несколько раз перерабатывавший основные положения своей теории, что подтверждает «многослойность» и контекстуальную детерминированность этих социопрагматических феноменов.

В первоначальном варианте своей теории [28], открывшей в 1996 г. новую эру в исследовании невежливости в лингвистике, Дж. Калпепер, исходя из основных положений универсальной теории вежливости, выстроил парадигму из 5 суперстратегий невежливости, направленных на нанесение определенного морального урона адресату высказывания (на подрыв его социального лица): 1) bald on record impoliteness; 2) positive impoliteness; 3) negative impoliteness; 4) sarcasm or mock politeness; 5) withhold politeness. Все эти суперстратегии реализуются в речи отдельными стратегиями. Всего автор выделяет десять стратегий невежливости, направленных на нанесение урона позитивному лицу адресата, и пять стратегий, направленных на нанесение урона негативному лицу адресата $[28$, p. 356-358].

В последующих двух версиях теории Дж. Калпепера «impoliteness» является зонтичным термином для объединения многих видов невежливого / грубого (не)речевого поведения, включая «boldness» (наглость); «boorishness» (грубость, хамство); «coarseness» (грубость, невежливость, непристойность); «flippancy» (непочтительность, дерзость); «incivility» (невежливость, неучтивость, невоспитанность); «inconsideration» (невнимание к другим); «insolence» (оскорбительное высокомерие, надменность); «irreverence» (непочтительность, неуважение); «rudeness» (грубость); «unmannerliness» (невоспитанность, невежливость, грубость) [23, p. 3233; 27, p. 24]. 
Во второй, созданной с опорой на дискурсивный анализ высказываний, версии своей теории Дж. Калпепер отмечает, что «невежливость зарождается тогда, когда: 1) адресант намеренно осуществляет атаку на лицо адресата и 2) адресат осознает и / или воссоздает данное поведение как намеренно атакующее его лицо или как одновременное проявление первого и второго действий. ...Становится понятно, что невежливость, как и вежливость, проявляется во взаимодействии говорящего и слушающего» [24, p. 38] (перевод мой. $-B$. Л.). Значительная роль в этой версии теории отводится обязательному учету просодического оформления невежливых речений [26, p. 1560-1575].

В третьей, последней на данный момент, версии своей теории [23; 25; 27] Дж. Калпепер дает развернутое и структурированное определение всех видов неуместного, лико-ущемляющего коммуникативного поведения, обозначаемых научным термином «impoliteness» и понимаемых как негативное отношение к конкретным поступкам, совершенным в конкретной ситуации. В основе данного негативного отношения находятся ожидания, желания и / или убеждения коммуникантов, связанные в том числе с тем, как самобытность, идентичность конкретной личности или группы поддерживается другими коммуникантами в ходе их взаимодействия. Поведенческие поступки адресанта, обусловленные данной ситуацией, оцениваются негативно в случае их несоответствия ожиданиям адресата относительно них или если они противоречат представлениям самого адресата. Эти поступки имеют эмоциональные последствия по крайней мере для одного коммуниканта, так как они либо оскорбляют адресата, либо могут быть для него оскорбительными. Ряд факторов усиливает восприятие того, насколько обидным (оскорбительным) кажется невежливое поведение, включая фактор того, считает ли адресат данный поступок намеренно оскорбительным или нет [23, p. 3233; 27, p. 23$].$

Так как коммуниканты часто воспринимают и описывают чужое коммуникативное поведение как невежливое или грубое, несмотря на свое понимание того, что их коммуникативный партнер не действовал намеренно, нет необходимости, по мнению Дж. Калпепе- ра, считать интенциональность обязательным условием при определении невежливости [23, p. 3233].

Их двух лексем английского языка, наиболее подходящих для обозначения нелицеприятного коммуникативного поведения адресанта, автор выбирает лексему «impoliteness», а не «rudeness», поскольку она, представляя собой очевидный контрапункт лексеме «politeness», весьма редко встречается в Оксфордском корпусе английского языка: в нем зафиксировано не более 30 примеров ее употребления [23, p. 3233; 27, p. 24].

Исключив из определения термина «impoliteness» признак интенциональности, намеренности (не)речевых действий адресанта, Дж. Калпепер сделал акцент на ожиданиях, желаниях адресата, проявляющихся в ходе коммуникации, связав интерпретацию речевых и неречевых действий адресанта со стороны адресата с эмоциональным состоянием последнего, что во многом перекликается с охарактеризованной выше позицией М. Кинпоинтнеpa, а также с точкой зрения сторонников интеракционального (социологического) подхода в изучении (не)вежливости Д.-3. Ка́дара (D.Z. Kádár), и M. Хо (M. Haugh), полагающих, что лингвистическая (не)вежливость по сути своей представляет социальную практику («social practice») [47, p. 73-74].

Отметим, что сторонники социологического (интеракционального) подхода, не отрицая полностью концептуальных достижений дискурсивного подхода, особенно связанных с ролью адресата в оценке высказываний адресанта, считают, что нельзя принижать и роль адресанта, так как оба коммуниканта совместными усилиями выстраивают траекторию понимания всего коммуникативного процесса, включая оценку того или иного высказывания как (не)вежливого. При таком подходе значение конкретного высказывания «конструируется» в динамике совместными усилиями адресанта и адресата, а оценка речевых и неречевых действий связана с моральным состоянием коммуникантов, с набором их ожиданий, позволяющим им распознать конкретные социальные действия и значения как таковые [47, p. 6].

Все ожидания коммуникантов схематически распределяются по трем уровням (сло- 
ям) рефлексии. Индивидуальные ожидания (первый уровень) представляют собой вероятностные конвенции для оценки социальных действий и значений, сформированные на основе истории взаимодействия конкретного коммуниканта с другими людьми. Эти ожидания могут быть почти одинаковыми или очень похожими для представителей близких социальных групп, но, учитывая индивидуальность (уникальность) каждого коммуниканта, они никогда не будут одинаковыми для всех. Подобные личностные ожидания (нормы) связаны напрямую с понятием габитуса в терминах П. Бурдье (см. подробнее: [1, c. 32]). Групповые ожидания (второй уровень) - это ожидания, разделяемые всеми членами тех или иных легко опознаваемых communities of practice или социальных групп. Социальные ожидания (третий уровень) представляют собой нормы конкретной национальной культуры или общества (cultural/ societal), к которым относятся конвенции общества для оценки социальных действий и значений [36, p. 37; 47, p. 95].

В терминах P. Уоттса (R. Watts) дискурсивный («постмодернистский») подход в изучении грубости («rudeness») сочетается с основами теории концептуального смешения, или концептуальной интеграции («conceptual blending»), Ж. Фоконье (G. Fauconnier), сближающейся с теорией лингвистической метафоры [32, p. 2495].

Подобный подход интересен именно своей методикой. Не давая четкого определения невежливости (грубости), Р. Уоттс отмечает, что цель аналитика в исследовании невежливости (грубости) заключается не в интерпретации конкретного коммуникативного поведения как вежливого или грубого, а в понимании того, в какой момент сами коммуниканты находят подтверждение своей уже сделанной оценке данного высказывания как вежливого / грубого на основании личных ментальных концептуализаций. Дискурсивный анализ грубости означает моментальное, ситуативное наложение («картирование») высказываний на уже существующие когнитивные фреймы, включающие в себя и понятия неуместного поведения для разнообразных ситуаций. В таком случае подобное «картирование» высказываний должно сочетаться с основными по- ложениями дискурсивного подхода в изучении невежливости.

Отказ от употребления термина «impoliteness» Р. Уоттс объясняет тем, что поскольку коммуниканты в речи избегают не просто невежливости, а состояния конфликта, угрозы своему лицу и разногласий в межличностных отношениях, то подобное состояние дел следует обозначить термином «rudeness 1 » (понимание грубости с позиции участников коммуникации) [70, p. 290-292].

В теории Д. Бусфильда (D. Bousfield), coзданной в свете идеологии Politeness ${ }_{2}$, но также учитывающей понимание вежливости рядовыми носителями языка, то есть идеологию Politeness $_{1}$, отмечается, что невежливость («impoliteness»), являясь логической противоположностью вежливости, заключается в осуществлении адресантом преднамеренных интенционально необоснованных противоречивых речевых актов, угрожающих социальному лицу адресата. К обязательным условиям ее проявления относятся отсутствие коммуникативного смягчения, равнозначного вежливости в контекстах, в которых смягчение обязательно, и наличие преднамеренной агрессии со стороны адресанта, характеризующейся усилением, «активной поддержкой» и максимальным увеличением угрозы лицу адресата для усугубления причиняемого ему социального ущерба. Невежливость адресанта можно считать успешной и «результативной» в случае распознавания адресатом намерения адресанта нанести ущерб его лицу [18, p. 72]. В данной теории грубость («rudeness»), в отличие от невежливости, не интенциональна, не намеренна и всегда «зарождается» случайно [19, р. 111].

\section{5. Вместо заключения.}

Таким образом, положение дел на «фронте» изучения сложнейшего социокоммуникативного феномена невежливости в современной зарубежной прагматике, социолингвистике, конверсационном анализе и других лингвистических направлениях таково, что ученые до сих пор не пришли к единому мнению относительно концептуализации невежливости на теоретическом уровне.

Сложность нахождения консенсуса в понимании сути невежливости на теоретическом уровне подтверждается тем, что среди самих носителей языка часто наблюдаются разногла- 
сия в оценке конкретного (не)речевого действия как вежливого / невежливого. То, что воспринимается одним коммуникантом исключительно как вежливость, другой коммуникант оценивает прямо противоположно.

Отметим то, что даже вежливость не всегда оценивается однозначно как нечто хорошее, поскольку ее можно использовать в корыстных, манипуляционных целях [30, p. $168 ; 60$, p. 59 ; 69, p. 32], и в этом случае ее можно оценить как проявление невежливости.

Постепенное решение лингвистами теоретических проблем, связанных в целом с исследованием невежливости, видится, в частности, в том, что теоретики данной области знаний ощущают очевидную необходимость выйти за пределы классических теорий вежливости, объединить их с другими направлениями лингвистических исследований (например, с теорией идентичности), а также с нелингвистическими дисциплинами. Смешение методологий исследования невежливости зарубежными учеными привело к тому, что они все чаще применяют для анализа широкий спектр языковых данных (начиная от придуманных примеров, экспериментальных данных из заданий по завершению дискурсивных отрывков, ролевых игр и заканчивая реальными данными по межличностным контактам, получаемыми с привлечением лингвистических корпусов и в результате анкетирования участников межличностных контактов) [55, p. 7].

Дж. Калпепер утверждает, что невежливость заслуживает глубокого научного изучения, так как она обладает серьезными импликациями для межличностного общения и общества в целом и часто реализуется в речи при помощи очень креативных способов. Невежливость окружают различные мифы и неправильное понимание, которые надо постепенно нивелировать [25, p. 13]. С этим мнением трудно не согласиться.

\section{СПИСОК ЛИТЕРАТУРЫ}

1. Бурдье, П. Социальное пространство и генезис классов / П. Бурдье // Социология социального пространства. - М. ; СПб. : Институт социальной психологии : Алетейя, 2007. - С. 14-48.

2. Жельвис, В. И. «Анти-Грайс»: постулаты грубости как регулятора коммуникативного пове- дения / В. И. Жельвис // Жанры речи : сб. науч. ст. памяти К.Ф. Седова. - Саратов ; М. : Лабиринт, 2012. - Вып. 8. - С. 99-109.

3. Жельвис, В. И. Грубость как регулятор коммуникативного поведения / В. И. Жельвис // Бытие в языке : сб. науч. тр. к 80-летию В.И. Жельвиса. Ярославль : Изд-во ЯГПУ, 2011. - С. 258-289.

4. Ларина, Т. В. Категория вежливости в английской и русской коммуникативных культурах / Т. В. Ларина. - М. : Изд-во РУДН, 2003. - 316 с.

5. Ларина, Т. В. Невежливость и грубость в общении американцев / Т. В. Ларина, М. Л. Харлова // Вестник Новосибирского государственного университета. Серия: Лингвистика и межкультурная коммуникация. - 2015. - Вып. 3. - С. 34-42.

6. Ларина, Т. В. О грубости и коммуникативной этике в межкультурном аспекте: постановка проблемы / Т. В. Ларина, М. М. Козырева, А. А. Горностаева // Вестник Российского университета дружбы народов. Серия «Лингвистика». - 2012. - № 2. C. $126-133$.

7. Леонтьев, В. В. Агональная вербальная грубость футбольных болельщиков / В. В. Леонтьев // Экология языка и коммуникативная практика. 2014. - № 2. - C. 255-268.

8. Леонтьев, В. В. Дискурсивный поворот в теории лингвистической вежливости: к образованию теории лингвистической невежливости / В. В. Леонтьев // Коммуникативные аспекты современной лингвистики и лингводидактики. - Волгоград : Изд-во ВолГУ, 2012. - С. 222-228.

9. Леонтьев, В. В. Лингвистическая (не)вежливость: к проблеме содержания категории / В. В. Леонтьев // Экология языка и коммуникативная практика. -2016. -№ 1. - С. 70-83.

10. Леонтьев, В. В. Понятия невежливости и грубости в современной лингвистике / В. В. Леонтьев // Экология языка и коммуникативная практика. - 2013. - № 1. - С. 131-141.

11. Леонтьев, В. В. Стратегии невежливой коммуникации в компьютерном дискурсе / В. В. Леонтьев // Человек. Язык. Культура : сб. науч. ст., посвящен. 60-летнему юбилею проф. В.И. Карасика : в 2 ч. / отв. соред. В. В. Колесов, М. Влад. Пименова, В. И. Теркулов. - Киев : Изд. дом Д. Бураго, 2013. Ч. 1. - С. 714-723.

12. Руднева, Е. А. Антропология вежливости: общекультурные и локальные нормы взаимодействия / Е. А. Руднева // Антропологический форум. 2016. - № 30. - C. 215-242.

13. Харлова, М. Л. Концептуализация невежливости в английском и русском языках / М. Л. Харлова // Вестник РУДН. Серия «Лингвистика». 2014. - № 2. - C. 119-131.

14. Arndt, H. Intergrammar: Towards an Integrative Model of Verbal, Prosodic and Kinesic 
Choises in Speech / H. Arndt, R. Jenny. - Berlin ; N.Y. ; Amsterdam : Mouton de Gruyter, 1987.-462 p.

15. Aspects of Linguistic Impoliteness / D. Jamet, M. Jobert (eds.). - Newcastle upon Tyne : Cambridge Scholars Publishing, 2013. - $246 \mathrm{p}$.

16. Austin, J. P. M. Politeness revisited - the dark side / J. P. M. Austin // New Zealand Ways of Speaking English / A. Bell, J. Holmes (eds.). - Clevedon ; Philadelphia : Multilingual Matters, 1990. - P. 277-293.

17. Beebe, L. M. Polite fictions: Instrumental rudeness as pragmatic competence / L. Beebe // Linguistics and the Education of Language Teachers: Ethnolinguistic, Psycholinguistic and Sociolinguistic Aspects. Georgetown University Round Table on Languages and Linguistics 1995 / J. Alatis [et al.] (eds.). - Washington, DC : Georgetown University Press, 1995. - P. 154-168.

18. Bousfield, D. Impoliteness in Interaction / D. Bousfield. - Amsterdam ; Philadelphia : John Benjamins Publishing Company, 2008. - 284 p.

19. Bousfield, D. Researching impoliteness and rudeness: Issues and definitions / D. Bousfield // Interpersonal pragmatics / M. A. Locher, S. L. Graham (eds.). - Berlin ; N. Y. : Mouton De Gruyter, 2010. - P. 101-134.

20. Brown, P. Politeness: Some Universals in Language Usage / P. Brown, S. Levinson. $-2^{\text {nd }}$ ed. Cambridge : CUP, 1987. $-348 \mathrm{p}$.

21. Christie, Ch. Editorial / Ch. Christie // Journal of Politeness Research. - 2005. - Vol. 1, № 1. - P. 1-7.

22. Craig, R. The discourse of requests: Assessment of politeness approach / R. Craig, K. Tracy, F. Spisak // Human Communication Research. - 1986. Vol. 12, № 4. - P. 437-468.

23. Culpeper, J. Conventionalized impoliteness formulae / J. Culpeper // Journal of Pragmatics. - 2010. Vol. 42. - P. 3232-3245.

24. Culpeper, J. Impoliteness and entertainment in the television quiz show / J. Culpeper // Journal of Politeness Research. - 2005. - Vol. 1, № 1. - P. 35-72.

25. Culpeper, J. Impoliteness: Questions and answers / J. Culpeper // Aspects of Linguistic Impoliteness / D. Jamet, M. Jobert (eds.). - Newcastle-upon-Tyne : Cambridge Scholars Publishing, 2013. -P. 2-16.

26. Culpeper, J. Impoliteness revisited: With special reference to dynamic and prosodic aspects / J. Culpeper, D. Bousfield, A. Wichmann // Journal of Pragmatics. - 2003. - Vol. 35, № 10-11. - P. 1545-1579.

27. Culpeper, J. Impoliteness: Using Language to Cause Offence/J.Culpeper-Cambridge: CUP, 2011. -292p.

28. Culpeper, J. Towards anatomy of impoliteness / J. Culpeper // Journal of Pragmatics. - 1996. - Vol. 25, №3. - P. 349-367.

29. Discursive Approaches to Politeness / Linguistic Politeness Research Group (eds.). - Berlin ; Boston : Mouton de Gruyter, 2011. -272 p.
30. Eelen, G. A Critique of Politeness Theories / G. Eelen. $-2^{\text {nd }}$ ed. - L. ; N. Y. : Routledge, 2014. -280 p. 31. Eelen, G. Politeness and ideology / G. Eelen // Pragmatics. - 1999. - Vol. 9, № 1. - P. 163-173.

32. Fauconnier, G. Conceptual blending / G. Fauconnier // International Encyclopedia of the Social and Behavioral Sciences. - Oxford : Elsevier Ltd., 2001. - P. 2495-2498.

33. Fraser, B. The association of deference with linguistic form / B. Fraser, W. Nolen // International Journal of Social Linguistics. - 1981. - Vol. 27, № 1.P. 93-109.

34. Garcés-Conjeos Blitvich, P. A genre approach to the study of im/politeness / P. Garcés-Conjeos Blitvich // International Review of Pragmatics. - 2010. Vol. 2. - P. 46-94.

35. Goffman, E. Interaction Ritual: Essays on Face-to-Face Behavior / E. Goffman. - N. Y. : Anchor Books, 1967. $-270 \mathrm{p}$.

36. Haugh, M. Impoliteness and taking offence in initial interaction / M. Haugh // Journal of Pragmatics. -2015 . - Vol. 86. - P. 36-42.

37. Holtgraves, T. Social psychology, cognitive psychology and linguistic politeness / T. Holtgraves // Journal of Politeness Research. - 2005. - Vol. 1, № 1. - P. 73-93.

38. Impoliteness and emotions in a cross-cultural perspective / J. Culpeper, G. Schauer, L. Marti, M. Nevala // SPELL: Swiss Papers in English Language and Literature. - 2014. - Vol. 30 - P. 67-88.

39. Impoliteness in Language. Studies on its Interplay with Power in Theory and Practice / D. Bousfield, M. Locher (eds.). - Berlin : Mouton De Gruyter, 2008. $-348 \mathrm{p}$.

40. Intercultural Pragmatics. - 2010. - Vol. 7, № 4. - P. 535-727.

41. Interdisciplinary perspectives on im/ politeness / M. Terkourafi, S. Defibaugh (eds.). Amsterdam; Philadelphia : John Benjamins Publishing Company, 2015. $-280 \mathrm{p}$.

42. Interpersonal Pragmatics / M. A. Locher, S. L. Graham (eds.). - Berlin ; Boston : Mouton De Gruyter, 2010. $-496 \mathrm{p}$.

43. Journal of Politeness Research. -2008 . - Vol. 4, №2. - P. 161-337.

44. Journal of Politeness Research. -2010. - Vol. 6, № 2. - P. 161-285.

45. Journal of Politeness Research. -2011. - Vol. 7 , № 2. - P. 159-292.

46. Journal of Pragmatics. - 2012. - Vol. 44, № 9.P. 1017-1133.

47. Kádár, D. Z. Understanding Politeness /D. Z. Kádár, M. Haugh.-Cambridge:CUP, 2013.-296 p.

48. Kasper, G. Linguistic politeness: Current research issues / G. Kasper // Journal of Pragmatics. 1990. -Vol. 14, № 2. - P. 193-218. 
49. Kienpointner, M. Impoliteness and emotional arguments / M. Kienpointner // Journal of Politeness Research. - 2008. - Vol. 4, № 2. - P. 243-265.

50. Kienpointner, M. Varieties of rudeness / M. Kienpointner // Functions of Language. - 1997. Vol. 4, № 2. - P. 251-287.

51. Lachenicht, L. G. Aggravating language: a study of abusive and insulting language / L. G. Lachenicht // Papers in Linguistics. - 1980. - Vol. 13, №4. - P. 607-687.

52. Lakoff, R.T. The limits of politeness: Therapeutic and courtroom discourses / R. T. Lakoff// Multilingua. 1989. - Vol. 8, № 2/3. - P. 101-129.

53. Lakoff, R. T. The logic of politeness or minding your P's and Q's / R. T. Lakoff// Papers from the Ninth Regional Meeting of Chicago Linguistic Society / Cl. Corum [et al.] (eds.). - Chicago : Chicago Linguistic Society, 1973. - P. 292-305.

54. Leech, G. Principles of Pragmatics / G. Leech. L. ; N. Y. : Longman, 1983. -250 p.

55. Locher, M. Interpersonal pragmatics and it's link to (im)politeness research / M. Locher // Journal of Pragmatics. - 2015. - Vol. 86. - P. 5-10.

56. Locher, M. Politeness theory and relational work / M. Locher, R. Watts // Journal of Politeness Research. - 2005. - Vol. 1, № 1. - P. 9-33.

57. Locher, M. Relational work and impoliteness: Negotiating norms of linguistic behavior / M. Locher, R. Watts // Impoliteness in Language. Studies on its Interplay with Power in Theory and Practice/D. Bousfield, M. Locher (eds.). - Berlin : Mouton de Gruyter, 2008. - P. 77-99.

58. Mills, S. Discursive approaches to politeness and impoliteness / S. Mills // Discursive Approaches to Politeness / Linguistic Politeness Research Group (eds.). Berlin ; Boston : Mouton de Gruyter, 2011.-P. 1-17.

59. Mills, S. Gender and impoliteness / S. Mills // Journal of Politeness Research. - 2005. -Vol. 1, № 2. P. 263-280.

60. Mills, S. Gender and Politeness / S. Mills. Cambridge : CUP, 2003. -270 p.

61. New perspectives on (im)politeness and interpersonal communication / Amaya L. Fernández, M. de la O Hernandez Lópes [et al.] (eds.). - Newcastle upon Tyne: Cambridge Scholars Publishing, 2012. - 278 p.

62. Penman, R. Facework and politeness: Multiple goals in courtroom discourse / R. Penman // Multiple goals in discourse / K. Tracy, N. Coupland (eds.). Clevedon; Buffalo ; Toronto : Multilingual Matters Ltd., 1990. - P. 15-38.

63. Pragmatics. - 2008. - Vol. 18, №4. - P. 563-802.

64. Sifianou, M. Linguistic politeness: Laying the foundations / M. Sifianou // Interpersonal Pragmatics / M. A. Locher, S. L. Graham (eds.). - Berlin ; Boston : Mouton De Gruyter, 2010. - P. 43-101.

65. Teaching and learning (im)politeness / B. Pizziconi, M. Locher (eds.). - Berlin ; Boston : Mouton de Gruyter, 2015. - 272 p.
66. Terkourafi, M. Toward a unified theory of politeness, impoliteness and rudeness / M. Terkourafi // Impoliteness in Language. Studies on its Interplay with Power in Theory and Practice / D. Bousfield, M. Locher (eds.). - Berlin : Mouton de Gruyter, 2008. - P. 45-74.

67. Watts, R. Introduction/R. Watts, S. Ide, K. Enlich // Politeness in Language: Studies in its History, Theory and Practice/R. Watts, S. Ide, K. Enlich (eds.). $-2^{\text {nd }}$ ed. Berlin ; N. Y. : Mouton de Gruyter, 2005. - P. 1-17.

68. Watts, R. Linguistic politeness theory and its aftermath: Recent research trends / R. Watts // Interpersonal pragmatics / M. A. Locher, S. L. Graham (eds.). - Berlin ; N. Y. : Mouton De Gruyter, 2010. - P. 43-70.

69. Watts, R. Politeness / R. Watts. - Cambridge : CUP, 2003. -308 p.

70. Watts, R. Rudeness, conceptual blending theory and relational work / R. Watts // Journal of Politeness Research. - 2008. - Vol. 4, № 2. - P. 289-317.

\section{REFERENCES}

1. Bourdie P. Sotsialnoe prostranstvo i genezis klassov [The Social Space and Genesis of Classes]. Sotsiologiya sotsialnogo prostranstva [The Sociology of Social Space]. Moscow; Saint Petersburg, Institut sotsialnoy psikhologii Publ.;Aleteya Publ., 2007, pp. 14-48.

2. Zhelvis V.I. «Anti-Grays»: postulaty grubosti kak regulyatora kommunikativnogo povedeniya ["Anty-Grice": The Postulates of Rudeness as a Regulator of Communicative Behavior]. Zhanry rechi: sb. nauch. st. pamyati K.F. Sedova [Speech Genres: Collected Papers in Memory of K.F. Sedov]. Saratov; Moscow, Labirint Publ., 2012, iss.8, pp. 99-109.

3. Zhelvis V.I. Grubost kak regulyator kommunikativnogo povedeniya [Rudeness as a Regulator of Communicative Behavior]. Bytie vyazyke: sb. nauch. tr. $k$ 80-letiyu V.I. Zhelvisa [The Being in Language: Collected Papers to the 80th Anniversary of V.I. Zhelvis]. Yaroslavl, Yaroslavl State University Publ., 2011, pp. 258-289.

4. Larina T.V. Kategoriya vezhlivosti v angliyskoy $i$ russkoy kommunikativnykh kulturakh [The Category of Politeness in English and Russian Linguacultures]. Moscow, Izd-vo RUDN, 2003. 316 p.

5. Larina T.V., Kharlova M.L. Nevezhlivost i grubost v obshchenii amerikantsev [Impoliteness and Rudeness in the Communication of Americans]. Vestnik Novosibirskogo gosudarstvennogo universiteta. Seriya Lingvistika i mezhkulturnaya kommunikatsiya, 2015, no. 3,pp. 34-42.

6. Larina T.V., Kozyreva M.M., Gornostayeva A.A. O grubosti i kommunikativnoy etike $\mathrm{v}$ mezhkulturnom obshchenii: $\mathrm{k}$ postanovke problemy [On Rudeness and Communicative Ethics in Intercultural Communication: to the Statement of Problem]. Vestnik 
Rossiyskogo universiteta druzhby narodov. Seriya «Lingvistika», 2012, no. 2, pp. 126-133.

7. Leontyev V.V. Agonalnaya verbalnaya grubost futbolnykh bolelshchikov [Agonal Verbal Rudeness in Speech Behavior of Football Fans]. Ekologiya yazyka i kommunikativnaya praktika, 2014, no. 2, pp. 255-268.

8. Leontyev V.V. Diskursivnyy povorot $\mathrm{v}$ teorii lingvisticheskoy vezhlivosti: k obrazovaniyu teorii lingvisticheskoy nevezhlivosti [Discourse Turn in the Theory of Linguistic Politeness: To the Formation of the Theory of Linguistic Impoliteness]. Kommunikativnye aspekty sovremennoi lingvistiki i lingvodidaktiki [Communicative Aspects of Contemporary Linguistics and Lingua-Didactics]. Volgograd, Izd-vo VolGU, 2012, pp. 222-228.

9. Leontyev V.V. Lingvisticheskaya (ne)vezhlivost: $\mathrm{k}$ probleme soderzhaniya kategorii [Linguistic (im)politeness: on Category Content]. Ekologiya yazyka i kommunikativnaya praktika, 2016, no. 1, pp. 70-83.

10. Leontyev V.V. Ponyatiya nevezhlivosti i grubosti $\mathrm{v}$ sovremennoy lingvistike [Notions of Politeness and Impoliteness in Contemporary Linguistics]. Ekologiya yazyka i kommunikativnaya praktika, 2013, no. 1, pp. 131-141.

11. Leontyev V.V. Strategii nevezhlivoy kommunikatsii v kompyuternom diskurse [The Strategies of Impolite Communication in ComputerMediated Discourse]. Kolesov V.I., Pimenova M. Vlad., Terkulov V.I., eds. Chelovek. Yazyk. Kultura: sb. nauch. st., posvyashchen. 60-letnemu yubileyu prof. V.I. Karasika: v 2 ch. [A Human Being. Language. Culture: Collection of Papers in the Honor of the 60th Anniversary of Prof. V.I. Karasik. In 2 parts. Part 1]. Kiev, Dm. Burago Publ., 2013, pp. 714-723.

12. Rudneva E.A. Antropologiya vezhlivosti: obshchekulturnye i lokalnye normy vzaimodeystviya [Anthropology of Politeness: Cultural and Local Interaction Norms]. Antropologicheskiy forum, 2016, no. 30 , pp. $215-242$.

13. Kharlova M.L. Kontseptualizatsiya nevezhlivosti v angliyskom i russkom yazykakh [The Conceptualization of Impoliteness and Rudeness in English and Russian]. Vestnik Rossiyskogo universiteta druzhby narodov. Seriya «Lingvistika», 2014, no. 2, pp. 119-131.

14. Arndt H., Jenny R. Intergrammar: Towards an Integrative Model of Verbal, Prosodic and Kinesic Choises in Speech. Berlin, N.Y., Amsterdam, Mouton de Gruyter, 1987. 462 p.

15. Jamet D., Jobert M., eds. Aspects of Linguistic Impoliteness. Newcastle upon Tyne, Cambridge Scholars, 2013. 246 p.

16. Austin J.P.M. Politeness revisited - the dark side. Bell A., Holmes J. New Zealand Ways of Speaking
English. Clevedon, Philadelphia, Multilingual Matters, 1990, pp. 277-293.

17. Beebe L.M. Polite fictions: Instrumental rudeness as pragmatic competence. Alatis J. et al., eds. Linguistics and the Education of Language Teachers: Ethnolinguistic, Psycholinguistic and Sociolinguistic Aspects. Georgetown University Round Table on Languages and Linguistics 1995. Washington, DC, Georgetown University Press, 1995, pp. 154-168.

18. Bousfield D. Impoliteness in Interaction. Amsterdam, Philadelphia, John Benjamins Publishing Company, 2008. 284 p.

19. Bousfield D. Researching impoliteness and rudeness: Issues and definitions. Locher M.A., Graham S.L., eds. Interpersonal pragmatics. Berlin, N.Y., Mouton De Gruyter, 2010, pp. 101-134.

20. Brown P., Levinson S. Politeness: Some Universals in Language Usage. 2nd ed. Cambridge, CUP, 1987.348 p.

21. Christie Ch. Editorial. Journal of Politeness Research, 2005, vol. 1, no. 1, pp. 1-7.

22. Craig R., Tracy K., Spisak F. The discourse of requests: Assessment of politeness approach. Human Communication Research, 1986, vol. 12, no. 4, pp. 437-468.

23. Culpeper J. Conventionalized impoliteness formulae. Journal of Pragmatics, 2010, vol. 42, pp. 3232-3245.

24. Culpeper J. Impoliteness and entertainment in the television quiz show. Journal of Politeness Research, vol. 1, no. 1, 2005, pp. 35-72.

25. Culpeper J. Impoliteness: Questions and answers. Jamet D., Jobert M., eds. Aspects of Linguistic Impoliteness. Newcastle-upon-Tyne, Cambridge Scholars, 2013, pp. 2-16.

26. Culpeper J., Bousfield D., Wichmann A. Impoliteness revisited: With special reference to dynamic and prosodic aspects. Journal of Pragmatics, 2003, vol. 35, no. 10-11, pp. 1545-1579.

27. Culpeper J. Impoliteness: Using Language to Cause Offence. Cambridge, CUP, 2011. 292 p.

28. Culpeper J. Towards anatomy of impoliteness. Journal of Pragmatics, 1996, vol. 25, no. 3, pp. 349-367.

29. Discursive Approaches to Politeness. Edited by Linguistic Politeness Research Group. Berlin, Boston, Mouton de Gruyter, 2011. 272 p.

30. Eelen G. A Critique of Politeness Theories. 2nd ed. L., N.Y., Routledge, 2014. 280 p.

31. Eelen G. Politeness and ideology. Pragmatics, 1999, vol. 9, no. 1, pp. 163-173.

32. Fauconnier G. Conceptual blending. International Encyclopedia of the Social and Behavioral Sciences. Oxford, Elsevier Ltd., 2001, pp. 2495-2498.

33. Fraser B., Nolen W. The association of deference with linguistic form. International Journal of Social Linguistics, 1981, vol. 27, no. 1, pp. 93-109. 
34. Garcés-Conjeos Blitvich P. A genre approach to the study of im/politeness. International Review of Pragmatics, 2010, vol. 2, pp. 46-94.

35. Goffman E. Interaction Ritual: Essays on Faceto-Face Behavior. N.Y., Anchor Books, 1967. 270 p.

36. Haugh M. Impoliteness and taking offence in initial interaction. Journal of Pragmatics, 2015, vol. 86, pp. 36-42.

37. Holtgraves T. Social psychology, cognitive psychology and linguistic politeness. Journal of Politeness Research, 2005, vol. 1, no. 1, pp. 73-93.

38. Culpeper J., Schauer G., Marti L., Mei M., Nevala M. Impoliteness and emotions in a crosscultural perspective. SPELL: Swiss Papers in English Language and Literature, 2014, vol. 30, pp. 67-88.

39. Bousfield D., Locher M., eds. Impoliteness in Language. Studies on its Interplay with Power in Theory and Practice. Berlin, Mouton De Gruyter, 2008. 348 p.

40. Intercultural Pragmatics, 2010, vol. 7, no. 4, pp. 535-727.

41. Terkourafi M., Defibaugh S. ed. Interdisciplinary Perspectives on Im/politeness. Amsterdam, Philadelphia, John Benjamins Publishing Company, 2015. 280 p.

42. Locher M.A., Graham S.L., ed. Interpersonal Pragmatics. Berlin, Boston, Mouton De Gruyter, 2010. $496 \mathrm{p}$.

43. Journal of Politeness Research, 2008, vol. 4, no. 2, pp. 161-337.

44. Journal of Politeness Research, 2010, vol. 6, no. 2, pp. 161-285.

45. Journal of Politeness Research, 2011, vol. 7, no. 2, pp. 159-292.

46. Journal of Pragmatics, 2012, vol. 44, no. 9 , pp. 1017-1133.

47. Kádár D.Z., Haugh M. Understanding Politeness. Cambridge, CUP, 2013.296 p.

48. Kasper G. Linguistic politeness: Current research issues. Journal of Pragmatics, 1990, vol. 14, no. 2, pp. 193-218.

49. Kienpointner M. Impoliteness and emotional arguments. Journal of Politeness Research, 2008, vol. 4, no. 2, pp. 243-265.

50. Kienpointner M. Varieties of rudeness. Functions of Language, 1997, vol. 4, no. 2, 1997, pp. 251-287.

51. Lachenicht L.G. Aggravating language: a study of abusive and insulting language. Papers in Linguistics, 1980, vol. 13, no. 4, pp. 607-687.

52. Lakoff R.T. The limits of politeness: Therapeutic and courtroom discourses. Multilingua, 1989, vol. 8, no. 2/3, pp. 101-129.

53. Lakoff R.T. The logic of politeness or minding your P's and Q's. Papers from the Ninth Regional Meeting of Chicago Linguistic Society. Corum Cl. et al., eds. Chicago, Chicago Linguistic Society, 1973, pp. 292-305.
54. Leech G. Principles of Pragmatics. L., N.Y., Longman, $1983.250 \mathrm{p}$.

55. Locher M. Interpersonal pragmatics and it's link to (im)politeness research. Journal of Pragmatics, 2015, vol. 86, pp. 5-10.

56. Locher M., Watts R. Politeness theory and relational work. Journal of Politeness Research, 2005, vol. 1, no. 1, pp. 9-33.

57. Locher M., Watts R. Relational work and impoliteness: Negotiating norms of linguistic behavior. Bousfield D., Locher M., eds. Impoliteness in Language. Studies on its Interplay with Power in Theory and Practice. Berlin, Mouton de Gruyter, 2008, pp. 77-99.

58. Mills S. Discursive approaches to politeness and impoliteness. Discursive Approaches to Politeness. Edited by Linguistic Politeness Research Group. Berlin, Boston, Mouton de Gruyter, 2011, pp. 1-17.

59. Mills S. Gender and impoliteness. Journal of Politeness Research, 2005, vol. 1, no. 2, pp. 263-280.

60. Mills S. Gender and Politeness. Cambridge, CUP, 2003. 270 p.

61. Fernández Amaya L., de la O Hernandez Lypes M. et al., eds. New Perspectives on (Im)politeness and Interpersonal Communication. Newcastle upon Tyne, Cambridge Scholars, 2012.278 p.

62. Penman R. Facework and politeness: Multiple goals in courtroom discourse. Tracy K., Coupland N., eds. Multiple goals in discourse. Clevedon, Buffalo, Toronto, Multilingual Matters Ltd., 1990, pp. 15-38.

63. Pragmatics, 2008 , vol. 18 , no. 4, pp. 563-802.

64. Sifianou M. Linguistic politeness: Laying the foundations. Locher M.A., Graham S.L., eds. Interpersonal Pragmatics. Berlin, Boston, Mouton De Gruyter, 2010, pp. 43-101.

65. Pizziconi B., Locher M. ed. Teaching and Learning (Im)politeness. Berlin, Boston, Mouton de Gruyter, 2015.272 p.

66. Terkourafi M. Toward a unified theory of politeness, impoliteness and rudeness. Bousfield D., Locher M., eds. Impoliteness in Language. Studies on its Interplay with Power in Theory and Practice. Berlin, Mouton de Gruyter, 2008, pp. 45-74.

67. Watts R., Ide S., Enlich K. Introduction. Politeness in Language: Studies in its History, Theory and Practice. Berlin, N.Y., Mouton de Gruyter, 2005, pp. 1-17.

68. Watts R. Linguistic politeness theory and its aftermath: Recent research trends. Locher M.A., Graham S.L., eds. Interpersonal pragmatics. Berlin, N.Y., Mouton De Gruyter, 2010, pp. 43-70.

69. Watts R. Politeness. Cambridge, CUP Publ., $2003.308 \mathrm{p}$.

70. Watts R. Rudeness, conceptual blending theory and relational work. Journal of Politeness Research, 2008, vol. 4, no. 2, pp. 289-317. 
В.В. Леонтьев. Грубость грубости рознь: к 20-летию исследований речевой невежливости

\section{Information About the Author}

Victor V. Leontyev, Candidate of Sciences (Philology), Associate Professor, Department of Foreign Language Communication, Volgograd State University, Prosp. Universitetsky, 100, 400062 Volgograd, Russian Federation, leontiev_vgu@mail.ru, english@volsu.ru.

\section{Информация об авторе}

Виктор Владимирович Леонтьев, кандидат филологических наук, доцент кафедры иноязычной коммуникации, Волгоградский государственный университет, просп. Университетский, 100, 400062 г. Волгоград, Российская Федерация, leontiev_vgu@mail.ru, english@volsu.ru. 